\title{
Study on the Self-conscious and Confident Development in Folk Sport Culture*
}

\author{
Hongmei Li \\ Sports Department \\ Xiamen University of Technology \\ Xiamen, China 361024
}

\begin{abstract}
This paper discusses the self-conscious and confident development of folk sport culture from the macro level, meso-level and micro-level. It has been shown in the researches that it is required to enhance the supervision strength of functional government departments on folk sport culture to guarantee its top intellectual support on the macro-level; it is required to formulate the policy documents related to folk sport inheritance and protection on the meso-level to guarantee its connecting link between the preceding and the following; and it requires multiple approaches and multiple functions to conduct the practical development of folk sports on the micro-level.
\end{abstract}

Keywords-folk sport; self-conscious and confident; development

\section{INTRODUCTION}

The cultural self-consciousness and confidence mean that the people of a country, a region or a nationality shall have sufficient and full cognition, understanding and acknowledgement of their own culture and shall voluntarily and sanely sublate the advantage and disadvantage contents in the culture of their own countries, regions and nationalities. It was pointed out in the report of the 19th National Congress of the Communist Party of China that: the cultural confidence is the more fundamental, deeper and more enduring power in the development of a country and a nationality. The folk sport is the important component of culture and its cultural selfconsciousness and confidence can play the dominant role for promotion of great development and prosperity of the career of socialist culture with Chinese characteristics. It is the inevitable demands for the prosperity of current Chinese culture to promote the cultural self-consciousness degree, enhance the cultural confidence, boost the cultural creativity and realize the re-innovation of culture. The promotion of folk sport cultural self-esteem and confidence is actually to promote our folk sport to step on the stage of world sport and its final objective is self-development and realization of diversified development of culture under the background of globalization as well as the goal and dream of country and body building. This study mainly discusses the self-conscious and confident development of folk sport culture from three levels including macro level, meso-level and micro level.

*Fund project: Youth fund program of humanities and social sciences research of Ministry of Education (Project approval No.: 15YJC890014).

\section{MACRO-LEVEL: IMPROVEMENT OF SUPERVISION STRENGTH OF FUNCTIONAL GOVERNMENT DEPARTMENT ON THE FOLK SPORTS}

The inheritance of folk sports and protection of functions of local government are decisive and Irreplaceable. The government shall unite with various local Sports Bureau, Bureau of Education, Bureau of Culture, Bureau of Folk Affairs, Bureau of Tourist and other organizations to establish the organization and coordination institutions for folk sport inheritance and protection, perfect the market performance, establish various levels of information communication mechanism, fully motivate the effects of civil organizations and give play to their due macro-regulating functions and government actions. The government actions shall enhance the force of regulation for folk sport administration and shall proceed with such works through multiple channels and shall make the folk sport self-consciousness and confidence deeprooted in the minds of the common people. The government actions are mainly embodied in that: firstly, the government departments shall perfect the policies and measures related to development of folk sports and establish the effective and long-acting management mechanism; secondly, formulate corresponding folk sport development objectives, project development planning and financial support; give priority to develop certain folk sport events enjoyed by the common people; establish comprehensive folk sport service platform; provide multiple kinds of supports; thirdly, give play to the organization management and publicity; give full play to the leading functions; practically accomplish the tasks of leading the public to actively participate in folk sport activities on the mind level; actively broadcast the documents and rules related to folk sports, etc; fourthly, educate and lead all the citizens to put forth effort to excavate the excellent folk sport culture around us full of romantic charm of Chinese nationalities and put into practice. The government actions are to protect the folk sport and ensure it to obtain normal, orderly, stable, comprehensive and sustainable development and provide the top intellectual supports and spiritual guidance for the practical activities of folk sports.

\section{MESO-LEVEL: FORMULATION OF POLICY DOCUMENTS RELATED TO FOLK SPORT INHERITANCE AND PROTECTION}

It is required by the Resolution about Several Significant Issues on Deepening the Reform of Cultural Administrative 
System and Promotion of Great Development and Prosperity of Socialist Culture Issued by the Central Committee of the Communist Party of China to vigorously carry forward Chinese excellent traditional culture. The rich and colorful folk sport culture is the important component of Chinese excellent traditional culture. The government shall issue documents related to folk sport culture inheritance and protection to guarantee its rapid development. The meso-level protective system documents can combine with the regionalism of folk sports, be suitable to actual circumstances and guarantee such works to be conducted through multiple approaches and multiple functions. I: promote the self-conscientiousness and confidence of folk sport culture through application for World Heritage. The intangible cultural heritages are the precious wealth of people around the world. In 2001, the UNESCO announced the first batch of list of master works of intangible cultural heritages and the intangible cultural heritages received high attention of people. The Law of Protection of Intangible Cultural Heritage of PRC has entered the legislative procedures on the Standing Committee of the National People's Congress and the Chinese government has successively issued the policies for protection of intangible cultural heritages. Thereinto, the G.F.B issue in 2005 is undoubtedly the instructive guideline and protective documents. Carefully implement the working policies including "protection orientation, rescue first, reasonable use and inheritance and development", insist on the scientific protection concept, solidly accomplish the protection, inheritance and management of items in the list of intangible cultural heritages, strive to promote the protection of intangible cultural heritages to step on new stage and make active contributions to construct complete intangible cultural heritage protection system with Chinese characteristics, promote the great development and prosperity of culture, construct the common spiritual home of Chinese nation and meet the increasing spiritual and cultural needs of the masses[1]. Conduct protection and rescue of folk sport, actively conduct intangible cultural heritage declaration and win the development opportunities for folk sports based on the instructive guideline and protective documents. Secondly, establish the special research institute for folk sports and study, design and organize to compile the historical data of folk sports. The study, design and compilation of historical data of folk sports are undoubtedly the preliminary works for promotion of development of folk sport courses. Although the traditional ethnic sports have drawn the attention of the country and people have intensified the research strength on it, most of current researches still focus on the aspect of martial arts. While the classifications including health maintenance, civil sports and folk sports are still not common which are only briefly mentioned in the historical data and textbooks about various kinds of sports at most. It is suggested that the department for macro-control shall include the civil and folk sports while compiling the historical data of traditional ethnic sports. Establish the high-level research teams, conduct investigations, collection and compilation of folk sports and save them completely in the forms including video, picture, word and picture recording, etc. Thirdly, actively establish the civil and folk sport associations. The passing on of folk sports from generation to generation benefits by the diligent inheritance, belief and national spirit of ceaseless selfimprovement of people of our nation. The civil communications and coordination enhance the insisting on national culture and national tradition and shall become the important measure for the whole process of inheritance of folk sports. In view of the geographical relationship and ethnic group characters for the formation and development of folk sports, the encouragement and support for folk inheritors including artistes, etc and the promotion and encouragement of participation of local folk associations and organizations are the important approaches.

\section{MiCRO-LEVEL: TO CONDUCT Micro PraCticAl DEVELOPMENT OF FOLK SPORTS THROUGH MULTIPLE APPROACHES AND MULTIPLE FUNCTIONS}

Under the regulation on macro-level of folk sports and the guidance and protection on meso-level, we should proceed with micro practice and development according to specific conditions through multiple approaches and multiple functions I. strive to improve the folk sport culture quality of main body of folk sport culture. As the main body of folk sport culture, the development of the masses is undoubtedly the core for development of folk sports. We should also enhance the sense of identity towards folk sport culture from aspects including social mentality, thinking method, values, aesthetics and world view, etc of main body of folk sport itself so as to promote the self-esteem and confidence of folk sport culture. We should promote the cultural development to match and coordinate with economic development and continuously promote the overall economic development level and quality, realize the cultural confidence, form the most essential and lasting competitive advantages which is hard to be replaced with high cultural self-consciousness degree so as to meet the spiritual and cultural needs of the masses as well; we need also to strive to cultivate, innovate and develop the excellent folk sport culture which only belongs to the region and the nation based on the rich folk sport culture resources, deep cultural deposits and cultural characteristics with special charm of local places, because only the special and nation's culture is jointly respected by our world which possesses the most values of promotion. In addition, to enhance the "folk sport culture selfconsciousness" and promote the "folk sport culture confidence", we should also fully motivate the enthusiasm of all Chinese people to faithfully learn, cultivate and use Chinese excellent culture and motivate the enthusiasm for self-esteem, self-discipline and self-praise for Chinese excellent (traditional and modern) culture. And we should also strive to promote the Chinese excellent culture to create glory again in the inheritance, reform, development and innovation through the view of future, basing on the present and learning from foreign culture under the guarantee of sufficient culture selfconsciousness and full cultural confidence. II. Rely on the education department to take the folk sports into education system so as to obtain development opportunities. The school is the important position for sports broadcasting and the source for development of folk sports. From the development progress of western sports, plenty of the foreign folk sports like Britain outdoor sports, Korean taekwondo, Japanese judo mainly achieve the development of such programs by taking schools as centers and become the main bodies of western 
sports as well as further become the sport culture wealth of the entire mankind. The Chinese martial arts also achieve its modern spreading by taking schools as medium. To realize normalization, scientization and universalness of folk sports, the school is the source. Unfortunately, except for martial arts, the folk sports of our country have always been in the state of marginalization in school sports for a long time and most of such sports are just deemed as the games before or after classes but has not become a formal course to be taken into classroom teaching. To realize the transformation from subsports into mainstream sports, it is primary for the folk sports to enter into school and to realize the modern transformation by taking school as medium. It is impractical to take all the items into scope of school, therefore the functional education department currently should fully motivate the propagation effects of school and take some of the folk sport items into the teaching scope of school sport courses according to practical situations with conditions, construct characteristic local folk sport courses and promote the folk sport cultural quality of youth. The enhancement of folk sport education in school sports has active strategic meanings on the modernization progress of folk traditional sports. With the establishment of folk traditional sport disciplines, the folk sport items in the folk traditions shall gradually enter into the school and be integrated into the gradually improving education system. The school sports shall be integrated with state will and add the folk traditional "Sanmin sports" (national, civil and folk) items which can not only enrich the school sport contents but also is the important affair for carrying forward national spirits and inheriting the national traditional culture [2]. Thirdly, proceed with industrial development of folk sports. The sport industry is not only green and environmental-friendly industry but also is the sunrise industry. Currently, this industry has shown great functions. It can not only bring health body and mentality for the participants but also is the environmental-friendly industry with no pollution and low consumption and the development of sport industry can also change the consumption life habits. Currently, the consumption of many people has become the "consumption of fluorescent screen, television and computer families". The cellphone phubbers are even everywhere while there are fairly less outdoor green and healthy consumption. The lack of outdoor sports seriously damage people's physical and psychological health. And it will be a beautiful thing to let people enjoy the passion and enjoyment brought by sports in green and healthy environment. There are plenty landscape resources in China, including Shaolin, Nanputuo and other temple landscapes and the river and sea resources including Yangtze River and oceans in the south, and the Huashan Mountain in north as well as the Songshan Mountain in middle China and other advantages of landscape resources. And there has always been folk holidays in China including Spring Festival, Lantern Festival, Qingming Festival, Dragon Boat Festival and Mid-Autumn Festival, etc. And the religious beliefs including Duke Guan, Goddess Matsu, Avalokitesvara, Perduo, Dangjing and Life-Protecting God, etc. will be derived from such holidays. If we combine certain landscape resources with the folk customs and beliefs derived from certain holidays and integrally develop the characteristic folk sport items including dragon dance, lion dance, dragon boat race, Songjiang Battle Array, breast-clapping dance and Gaoja operas, etc, integrate the industrial functions of sports, culture and tourism and construct the industrial parks for folk sport culture leisure. The foot fighter in Fujian in south China is the typical case of industrial parks for folk sport culture leisure which has been successively operated. The activities of foot fighter rely on the tourism cultural resources in Mount Wuyi, its seminary and the group of sports consumption and take full advantage of the special natural environment of Mount Wuyi, take the urban image of "Mount Wuyi- seminary of foot fighter activity" as core and integrate the industrial functions of sports, culture and tourism to construct the "International Foot Fighter Leisure and Sports Industrial Park". This park is integrated with cultural functions, performance functions, exhibition functions, education functions and industrial functions which possesses huge industrial values and is also the green and low-carbon consumption. The industrial values of sport industrial park promote the development of foot fighter which, in turn, becomes the card for construction of national level important resort district and the both benefit from each other. Therefore, the industrialization of folk sports will definitely promote the rapid development of folk sports.

\section{CONCLUSION}

Currently, no matter it is the country that pays attention to the domestic environment of folk culture or it is the world that stresses the international environment of cultural globalization and diversification, they all provide good development space and soil for development of folk sports. Under this background, we have no reason to not to be full of confidence for the development of our folk sports. Therefore, every Chinese shall have sufficient cultural self-awareness and shall promote the individual consciousness to be integrated and become the collective consciousness so as to achieve cultural confidence and further use the transcendent cultural confidence to promote the overall improvement and the comprehensive glory of Chinese excellent culture quality.

\section{REFERENCES}

[1] State Council. Opinion on Enhancement of Protection Works for Intangible Cultural Heritage of Our Country of General Office of the State Council (G.F.B. (2005). No. 18). [EB/OL] (2005-03-26] [2018-510] http://www.gov.cn/zwgk/2005-08/15/content_21681.htm

[2] Li Jiyuan. Alienation Study on School Sports [J]. Journal of Tianjin University of Sport. 2008, 23 (4): 338-339. 